\title{
A Study of Personality and Family- and School Environment and Possible Interactional Effects in 244 Swedish Children-A Multiple Regression Analysis
}

\author{
Nils Bertil Gerhard Persson \\ Department of Psychology, Lund University, Lund, Sweden \\ Email: bertil.persson@psy.lu.se
}

Received 16 April 2014; revised 12 May 2014; accepted 2 June 2014

Copyright (C) 2014 by author and Scientific Research Publishing Inc. This work is licensed under the Creative Commons Attribution International License (CC BY). http://creativecommons.org/licenses/by/4.0/

C. (i) Open Access

\begin{abstract}
The aim of the study was to examine relationships between psychosocial family- and school environment and personality as assessed by the Junior Eysenck Personality Questionnaire (EPQ-J) and possible personality interactional effects. The study was based on 244 Swedish girls and boys, 10 19 years old, who filled in the Family- and School Psychosocial Environment (FSPE) questionnaire and the EPQ-J. A multiple regression analysis showed that the FSPE-factor family conflicts and school discipline predicts psychoticism (antisocial personality), and that the FSPE-factor warmth, support and openness from parents, siblings and peers predict extraversion. Sex, psychoticism and the size of sibling group predicted neuroticism. Spanking was reported in various degrees by 8.1 percent of the children, and this factor was related to psychoticism. These results support socialization theories. The most unexpected finding was the impact of interactions between personality variables themselves, influencing the FSPE's predictability of neuroticism. Discussion about the advantage of the use of statistic control in a multiple regression, possible causal links between psychosocial environment and personality, limitations and further research propositions concludes the article.
\end{abstract}

\section{Keywords}

Psychosocial Environment, Environmental Measure, Personality, Traits, Multiple Regression

\section{Introduction}

Theories postulate that socialization and gene-environment interaction influence children's personality devel-

How to cite this paper: Persson, N. B. G. (2014). A Study of Personality and Family- and School Environment and Possible Interactional Effects in 244 Swedish Children-A Multiple Regression Analysis. Psychology, 5, 886-895. 
opment from the very first day and onwards (Bornstein, 2006; Pomerantz \& Thompson, 2008). Consequently, the importance of the development of environmental measures has also been emphasised in behavioural genetic research (Reiss, Plomin, Hetherington, Howe, Rovine, Tryon, \& Stanley, 1994; Vernon, Jang, Harris, \& McCarty, 1997; Plomin \& Daniels, 2011). Compared to the huge amount of personality tests available, few standardized environmental measures have been constructed. In order to study relationships between psychosocial environment and personality, a variety of environmental measures are needed. A standardized Swedish measure, Family- and School Psychosocial Environment (FSPE), is available and covers both current familialand extra-familial (school) environmental factors. The form also includes items in which children rate their family environment in comparisons with a sibling (Persson, 2011). The primary goal of the current study was to investigate psychosocial factors predictability of the personality traits extraversion, neuroticism and psychoticism/antisocial personality, and possible personality interactional effects on such predictions.

Harsh discipline, such as spanking, is prohibited by law in Sweden since 1979. However, this does not mean that parents do not spank their children anymore. If studies allow children to be anonymous, they can report spanking without any inconvenient consequences. A study, conducted on Swedish children in middle class and in junior high, showed that 11.1 percent had been spanked sometimes or often, and 1.7 percent had been spanked very often (Svensson, Långberg, \& Janson, 2007). Spanking has also been documented in migraine families (Persson, 1997). In that study, migraineurs experienced significantly more spanking than migraine-free siblings. Does spanking relate to personality factors such as extraversion, neuroticism and psychoticism/antisocial personality?

The absolute rating approach yields information about the degree or perceived impact of psychosocial environments, e.g. how much parental warmth the children receive related to a certain scale. Such rating gives information about how much parental warmth they get compared to other individuals in the sample. The relative rating approach yields information about the degree of perceived psychosocial environments in comparisons with a specific sibling. Do these different types of ratings yield similar or different results?

\section{Research Questions in the Present Study}

The aim of this study was to assess the relationship between current psychosocial environment measured by the Family- and School Psychosocial Environment (FSPE) and personality measured by the Junior Eysenck Personality Questionnaire (J-EPQ). Does psychosocial environment, including spanking, predict the personality variables extraversion, neuroticism and psychoticism/antisocial personality according to the socialization theories? Do gender, age, size of sibling group and social desirability (the Lie scale in J-EPQ) also matter and influence the prediction outcome?

Personality traits are supposed to be uncorrelated, but this is seldom true (Bäckström, Björklund, \& Larsson, 2009). Do personality variables correlate in the present study, and if so, do they account for correlations seen between psychosocial environment (FSPE) and personality (J-EPQ)?

Further, does relative ratings of differential parental treatment in comparisons with a sibling relate to personality?

\section{Method}

\subsection{Participants}

Children (10 - 19 years of age) from the southwest part of Sweden, with at least one sibling, completed the FSPE and J-EPQ $(\mathrm{N}=244)$. Boys and girls were equally represented in the sample $(50.2 \%$ girls; $49.8 \%$ boys $)$. The mean age was 13.7 years for girls $(S D=2.22)$ and 13.9 years for boys $(S D=2.22)$.

\subsection{Measures}

Family- and School Psychosocial Environment (FSPE):

The FSPE is a Swedish standardized, factor analyzed and cross-validated environmental measure (Persson, 2011). The 26 items in FSPE cover subject-parent-, subject-sibling-, subject-teacher- and subject-peer relations and events in those relations. The form comprises six primary factors: Parental warmth and support (FSPE1); School discipline (FSPE2); Sibling warmth (FSPE3); Family openness (FSPE4); Family conflicts (FSPE5); and Peer relations and support (FSPE6). Inter-item reliabilities range from 0.61 to 0.78 . 
Two higher-order factors were chosen in the present study because they possess more adequate psychometric properties:

1) Warmth, support and openness from parents, siblings and peers (FSPE:1). Examples: "My parents hug me", "My parents take me to different places when I need it", "Me and my parents have fun together", "My parents help me with homework", "Siblings say they like me" and "I get invited to my pals' parties" (Cronbach's $\alpha=$ $0.82)$.

2) Family conflicts and school discipline (FSPE:2). Examples: "My parents yell at each other", "My parents spank me", "Siblings tease me and hit me", Teachers send complaints to my parents", "Teachers banish me from the classroom" and "Teacher retain me in school after class" (Cronbach's $\alpha=0.71$ ).

The items were answered on a 4-point Likert scale: $0=$ Never, $1=$ Sometimes, $2=$ Often, $3=$ Very often.

In the Family Psychosocial Environment (FPE, part 2 of the FSPE) the subjects responded to 10 items regarding subject-parent relations in comparison with the sibling closest in age. The FPE consists of two factors: Parental warmth and offers (FPE1) and Parental discipline (FPE2).

The subjects were asked how the parents use to treat them and the chosen sibling. The items start with "I get..." and end with “... than my sibling”. The ten items were: hugs, kisses, praise, complaints, scolding, smacking, things, help, presents and choices. The children were responding to each item by selecting one of the following alternatives: 1 = much less than my sibling; 2 = less than my sibling; $3=$ the same as my sibling; $4=$ more than my sibling; 5 = much more than my sibling.

The Junior-Eysenck Personality Questionnaire (J-EPQ):

The J-EPQ is a factor analyzed and cross-validated personality test that consists of three personality factors and has been standardized on a Swedish population (Eysenck, von Knorring, \& von Knorring, 1988):

1) Extraversion (E): the 24 items relate to impulsivity and sociability. Examples: "Do you like exiting things to happen?", "Do you have many friends?", "Do you like to tell jokes to your friends?” (Cronbach's $\alpha=0.73$ ).

2) Neuroticism (N): the 22 items relate to traits such as nervousness and sensibility. Examples: "Do you often feel that life is boring?”, “Are you usually worried that terrible things will happen?”, "Do you often have nightmares?” (Cronbach's $\alpha=0.84$ ).

3) Psychoticism/antisocial personality (P): the 21 items relate to unfriendliness and coldness. Examples: "Do you sometimes like to see when a gang mob younger kids?”, "Do you want to hurt people you actually like?”, "Do you wish other children being afraid of you?" (Cronbach's $\alpha=0.64)$. The scale correlates negatively with the big five personality traits Agreeableness and Conscientiousness (Costa Jr. \& McCrae, 1995) and, in comparisons with other traits, possesses the highest effect-size value accounting for antisocial behaviour (Miller \& Lynam, 2001).

4) Lie (L), or social desirability response, is a validation scale. The scale consists of 22 items (Cronbach's $\alpha=$ 0.78). Examples: "Do you always obey when you are told?", "Have you ever cheated in a game or play?", "Have you ever stolen something?”.

\subsection{Procedure}

Twenty-two teachers in elementary schools and gymnasiums were contacted by mail. Eleven teachers responded and the rest did either decline or did not answer the request. The teachers acted as test leaders in their classrooms, following written instructions given by the author. No attrition was reported by the teachers, but it was assumed that some pupils were sick and that some had no siblings (approximately $14 \%$ of all school children at age 13 have no siblings, according to Statistics Sweden, SCB, 2008). The FPE form was designed for children with at least one sibling. The children completed the FSPE/FPE and J-EPQ anonymously. Only age, sex, family size (sibling group) and test scores were recorded.

A correlation- and a hierarchical multiple regression analysis was done in order to answer the research questions.

\section{Results}

The relationship between psychosocial environment (FSPE) and personality (J-EPQ) was examined. Several correlations were found, including personality variables themselves (see Table 1). Twenty-one of 36 correlations (i.e. 58.3\%) were significant at alfa 0.05 .

Three models were tested in a hierarchical multiple regression analysis. In the first model, sex, age, sibling 
group and lie were entered as predictive variables. In the second model, the psychosocial environment factors (FSPE) were entered as predictive variables and in the third and final model the personality variables (J-EPQ) were included. Each personality variable was entered as response variable (see Table 2). Beta estimates, adjusted $\mathrm{R}^{2}$ and $\mathrm{R}^{2}$-change are presented (non-significant predictors are excluded from the model).

The second- and third regression model is of major interest. First, does psychosocial environment predict personality, and second, do personality variables alter such predictions, i.e. act as potential mediating factors?

\subsection{Psychoticism/Antisocial Personality}

The inclusion of family conflicts and school discipline (FSPE:2) and warmth, support and openness from parents, siblings and peers (FSPE:1) as predictor variables improved the model substantially, indicated by a highly significant $\mathrm{R}^{2}$-change. Hence, both FSPE factors were significant predictors of psychoticism/antisocial personality $(\beta=-0.17$ and $\beta=0.31)$. Sex and lie were also significantly related to psychoticism/antisocial personality. All together, the FSPE factors, sex, and Lie accounted for $35.6 \%$ of the variance in psychoticism/antisocial personality. Further, spanking accounted for 6 percent of the variance in psychoticism/antisocial personality ( $\beta=$ $0.25 ; p<0.001)$. Spanking was captured by item 20, within the FSPE factor Family conflicts and school discipline.

In the final model, the personality variables Neuroticism and Extraversion (J-EPQ) were also included as predictor variables. The relationship between family conflicts and school discipline (FSPE:2) and psychoticism/ antisocial personality was somewhat altered by neuroticism, as indicated by a lower beta value $(\beta=0.25)$ and a higher adjusted $\mathrm{R}$ square $\left(\mathrm{R}^{2}=0.42\right)$. Further, sex was strengthened as a predictor of psychoticism/antisocial personality when neuroticism was entered in the model $(\beta=0.31)$. The Bonferroni's stricter requirement for significance was fulfilled in all predictions, except for FSPE:1 and extraversion.

\subsection{Extraversion}

The inclusion of warmth, support and openness from parents, siblings and peers (FSPE:1) improved the model substantially. FSPE: 1 was a significant predictor of extraversion $(\beta=0.31)$. Sex and lie were also significant predictors, and all together these factors accounted for 13.6 percent of the variance in extraversion.

The relationship between the FSPE:1 (warmth, support and openness from parents, siblings and peers) and extraversion was only slightly altered by the inclusion of other personality variables. The Bonferroni's stricter requirement for significance was fulfilled for FSPE:1 only.

Table 1. Inter-correlations between family and school psychosocial environment (FSPE), personality, sex, age and sibling group $(\mathrm{N}=244)$.

\begin{tabular}{|c|c|c|c|c|c|c|c|c|}
\hline & $\begin{array}{l}\text { Warmth, support and } \\
\text { openness from } \\
\text { parents (FSPE:1) }\end{array}$ & $\begin{array}{l}\text { Family conflicts and } \\
\text { school discipline } \\
\text { (FSPE:2) }\end{array}$ & Extraversion & Neuroticism & $\begin{array}{l}\text { Psychoticism/ } \\
\text { antisocial } \\
\text { personality }\end{array}$ & Lie & Sex & Age \\
\hline $\begin{array}{l}\text { Family conflicts and } \\
\text { school discipline } \\
\text { (FSPE:2) }\end{array}$ & $-0.17^{* *}$ & & & & & & & \\
\hline Extraversion & $0.28^{* * *}$ & 0.05 & & & & & & \\
\hline Neuroticism & -0.02 & $0.19^{* *}$ & $-0.15^{*}$ & & & & & \\
\hline $\begin{array}{c}\text { Psychoticism/ } \\
\text { antisocial personality }\end{array}$ & $-0.27^{* * *}$ & $0.47^{* * *}$ & $0.13^{*}$ & $0.23^{* * *}$ & & & & \\
\hline Lie & -0.02 & $-0.38^{* * *}$ & $-0.18^{* *}$ & -0.12 & $-0.39^{* * *}$ & & & \\
\hline Sex & $0.20^{* *}$ & $-0.15^{*}$ & $-0.16^{*}$ & $0.34^{* * * *}$ & $-0.34^{* * *}$ & 0.09 & & \\
\hline Age & $-0.14^{*}$ & $0.14^{*}$ & -0.01 & 0.11 & $0.21^{* *}$ & $-0.48^{* * *}$ & -0.05 & \\
\hline Sibling group & -0.06 & 0.05 & -0.05 & $0.20^{* *}$ & 0.06 & -0.04 & 0.05 & -0.04 \\
\hline
\end{tabular}

Notes: ${ }^{*} p<0.05,{ }^{* * *} p<0.01,{ }^{* * *} p<0.001 .{ }^{* * * *}$ Bonferroni's stricter requirement for significance is fulfilled. 
Table 2. Hierarchical multiple regression analysis which includes three models for each personality variable (i.e. response variables). The first model includes sex, age, sibling group and lie (social desirability). In the second model the FSPE environmental factors are added and in the third model the personality factors are added. Corresponding beta estimates, adjusted $\mathrm{R}^{2}$ and $\mathrm{R}^{2}$ change are presented $(\mathrm{N}=244)$. Non-significant predictors are excluded from the model.

\begin{tabular}{|c|c|c|c|c|c|c|c|}
\hline $\begin{array}{l}\text { Response } \\
\text { variables }\end{array}$ & Model & Predictors & $\mathrm{b}$ & S.E. & $\beta$ & $\mathrm{t}$ & $\begin{array}{c}\text { Model summary } \\
\text { Adj. } \mathrm{R}^{2} \\
\left(\mathrm{R}^{2} \text { change }\right)\end{array}$ \\
\hline \multirow[t]{9}{*}{ Extraversion } & \multirow[t]{2}{*}{1} & Sex & -0.981 & 0.439 & -0.140 & $-2.233^{*}$ & 0.054 \\
\hline & & Lie & -0.170 & 0.052 & -0.235 & $-3.289^{* * *}$ & \\
\hline & \multirow[t]{3}{*}{2} & Sex & -1.427 & 0.431 & -0.204 & $-3.310^{* * *}$ & 0.136 \\
\hline & & Lie & -0.139 & 0.054 & -0.192 & $-2.588^{* *}$ & $\left(0.088^{* * *}\right)$ \\
\hline & & $\begin{array}{l}\text { Warmth, support and openness from } \\
\text { parents, siblings and peers (FSPE:1) }\end{array}$ & 0.153 & 0.031 & 0.311 & $4.931^{* * *}$ & \\
\hline & \multirow[t]{4}{*}{3} & Lie & -0.109 & 0.055 & -0.151 & $-2.004^{*}$ & 0.159 \\
\hline & & $\begin{array}{l}\text { Warmth, support and openness from } \\
\text { parents, siblings and peers (FSPE:1) }\end{array}$ & 0.166 & 0.031 & 0.338 & $5.318^{* * *}$ & $\left(0.030^{*}\right)$ \\
\hline & & Neuroticism & -0.107 & 0.047 & -0.156 & $-2.261^{*}$ & \\
\hline & & $\begin{array}{l}\text { Psychoticism/ } \\
\text { antisocial personality }\end{array}$ & 0.221 & 0.091 & 0.189 & $2.433^{*}$ & \\
\hline \multirow[t]{9}{*}{ Neuroticism } & \multirow[t]{2}{*}{1} & Sex & 3.452 & 0.607 & 0.337 & $5.685^{* * *}$ & 0.156 \\
\hline & & Sibling group & 0.885 & 0.296 & 0.177 & $2.987^{* *}$ & \\
\hline & \multirow[t]{3}{*}{2} & Sex & 3.789 & 0.611 & 0.370 & $6.206^{* * *}$ & 0.191 \\
\hline & & Sibling group & 0.819 & 0.291 & 0.164 & $2.810^{* *}$ & $\left(0.041^{* *}\right)$ \\
\hline & & $\begin{array}{l}\text { Family conflicts and school discipline } \\
\text { (FSPE:2) }\end{array}$ & 0.308 & 0.093 & 0.211 & $3.301^{* * *}$ & \\
\hline & \multirow[t]{4}{*}{3} & Sex & 4.342 & 0.614 & 0.420 & $7.077^{* * * *}$ & 0.269 \\
\hline & & Sibling group & 0.742 & 0.277 & 0.148 & $2.675^{* *}$ & $\left(0.082^{* * *}\right)$ \\
\hline & & Extraversion & -1.199 & 0.088 & -0.136 & $-2.261^{*}$ & \\
\hline & & Psychoticism/antisocial personality & 0.591 & 0.120 & 0.344 & $4.931^{* * *}$ & \\
\hline \multirow{12}{*}{$\begin{array}{c}\text { Psychoticism/ } \\
\text { antisocial } \\
\text { personality }\end{array}$} & \multirow[t]{2}{*}{1} & Sex & -1.851 & 0.336 & -0.331 & $-5.509^{* * *}$ & 0.236 \\
\hline & & Lie & -0.209 & 0.040 & -0.338 & $-5.263^{* * *}$ & \\
\hline & \multirow[t]{4}{*}{2} & Sex & -1.418 & 0.317 & -0.238 & $-4.474^{* * *}$ & 0.356 \\
\hline & & Lie & -0.149 & 0.039 & -0.241 & $-3.772^{* * *}$ & $\left(0.123^{* * *}\right)$ \\
\hline & & $\begin{array}{l}\text { Warmth, support and openness from } \\
\text { parents, siblings and peers (FSPE:1) }\end{array}$ & -0.073 & 0.023 & -0.174 & $-3.192^{* *}$ & \\
\hline & & $\begin{array}{l}\text { Family conflicts and school discipline } \\
\text { (FSPE:2) }\end{array}$ & 0.260 & 0.048 & 0.306 & $5.360^{* * *}$ & \\
\hline & \multirow[t]{6}{*}{3} & Sex & -1.861 & 0.329 & -0.312 & $-5.664^{* * *}$ & 0.420 \\
\hline & & Lie & -0.128 & 0.038 & -0.208 & $-3.376^{* * *}$ & $\left(0.067^{* * *}\right)$ \\
\hline & & $\begin{array}{l}\text { Warmth, support and openness from } \\
\text { parents, siblings and peers (FSPE:1) }\end{array}$ & -0.086 & 0.023 & -0.204 & $-3.762^{* *}$ & \\
\hline & & $\begin{array}{l}\text { Family conflicts and school } \\
\text { discipline (FSPE:2) }\end{array}$ & 0.210 & 0.047 & 0.247 & $4.460^{* * *}$ & \\
\hline & & Extraversion & 0.111 & 0.046 & 0.130 & $2.433^{*}$ & \\
\hline & & Neuroticism & 0.159 & 0.032 & 0.273 & $4.931^{* * *}$ & \\
\hline
\end{tabular}

Notes: ${ }^{*} p<0.05,{ }^{* *} p<0.01,{ }^{* * *} p<0.001 .{ }^{* * *}$ Bonferroni's stricter requirement for significance is fulfilled. 


\subsection{Neuroticism}

Family conflicts and school discipline (FSPE:2) was a significant predictor of neuroticism $(\beta=0.21)$. The inclusion of the FSPE:2 as predictor variable (the second model) improved the model, indicated by a significant $\mathrm{R}^{2}$-change (see Table 2). Sex was a more powerful predictor, indicated by a higher beta value $(\beta=0.34)$. The size of sibling group was also a significant predictor of neuroticism $(\beta=0.16)$.

The inclusion of psychoticism/antisocial personality (third model) improved the model summery substantially, indicated by a highly significant $\mathrm{R}^{2}$-change, and family conflicts and school discipline (FSPE:2) was excluded from the model as a predictor of neuroticism. On the other hand, sex was strengthened as a predictor of neuroticism $(\beta=0.42)$ (see Table 2).

The Bonferroni's stricter requirement for significance was fulfilled in all predictions, except for sibling group and Extraversion.

\subsection{FSE-Factors and Correlations with Personality}

The children's ratings of differential parental treatment as in compared with a sibling closest in age (the FPE factors) correlated with extraversion, psychoticism/antisocial personality, lie and age (see Table 3). Children who experienced more parental warmth and offers, compared to a sibling (FPE1), had slightly higher extraversion scores than children who experienced less differential parental treatment in this regard. Children who experienced more parental discipline, compared to a sibling (FPE2) scored slightly higher on psychoticism/antisocial personality than children who experienced less differential parental treatment. Further, younger siblings experienced more parental warmth and offers (FPE1) compared to older siblings, and children who experienced more parental discipline had slightly lower Lie scores.

\section{Discussion}

The findings in the present study support the theories that predict that psychosocial/interpersonal factors during childhood and youth are systematically related to personality. Perceived environmental psychosocial factors, classified in FSPE as warmth, support and openness from parents, siblings and peers (FSPE:1) and family conflicts and school discipline (FSPE:2), relate to personality. Both factors were significant predictor of psychoticism/antisocial personality. Squared partial correlations showed that 5.7 and 7.3 per cent of the variance in psychoticism/antisocial personality was attributable to FSPE:1 and FSPE:2, respectively. Accordingly, psychoticism/antisocial personality was more pronounced in subjects who experienced family conflicts and discipline at school, and less pronounced in subjects who experienced warmth and support. Neuroticism was also related to family conflicts and discipline at school, but this association was more complicated than expected, a matter discussed later.

The present study supports the findings of Svensson et al. (2007), that spanking does occur among Swedish children. In the present study 8.1 percent of the children had been spanked: $6.9 \%$ sometimes; $0.8 \%$ often; $0.4 \%$ very often. The next question was whether spanking relates to personality, and the answer is yes although a rather small amount, six percent, of the variance in psychoticism/antisocial personality was related to spanking.

Table 3. Inter-correlations between personality and FPE (perceived differential treatment compared with a sibling), $(\mathrm{N}=241)$.

\begin{tabular}{ccc}
\hline & Parental warmth and offers (FPE1) & Parental discipline (FPE2) \\
\hline Parental discipline (FPE2) & -0.12 & 0.05 \\
Extraversion & $0.17^{* * *}$ & 0.01 \\
Neuroticism & -0.02 & $0.15^{*}$ \\
Psychoticism/antisocial personality & -0.11 & $-0.21^{* * *}$ \\
Lie & 0.08 & -0.07 \\
Sex & 0.08 & 0.03 \\
\hline
\end{tabular}

Notes: ${ }^{*} p \leq 0.05,{ }^{*} p \leq 0.01, \stackrel{* * *}{p} \leq 0.00$. FPE: Family Psychosocial Environment. 
Children who have been spanked are not always antisocial and children who have not been spanked are sometimes antisocial. Children who have been spanked but do not display antisocial behaviour may be described as "copers" and children who have not been spanked but display antisocial behaviour may be described as "troubled". Accordingly, other factors are involved.

Warmth, support and openness from parents, siblings and peers (FSPE:1) was a significant predictor of extraversion. Squared partial correlation showed that 10.7 per cent of the variance in extraversion was attributable to FSPE:1. Thus, introverted children experienced less warmth and support. Similar results have been documented in other studies (Clayer, Ross, \& Campbell, 1984; Jacobsson, Lindström, von Knorring, Perris, \& Perris, 1980; Kraft \& Zuckerman, 1999).

The predictive power of extraversion and psychoticism/antisocial personality increases substantially if more than the FSPE-variables are added to the regression model (indicated by increased adjusted $\mathrm{R}^{2} \mathrm{~s}$ ). Thus, psychosocial environment (FSPE) and sex, respectively, account for a unique portion of the variance in psychoticism/antisocial personality and extraversion. Sex differences were significant in both the FSPE- and J-EPQ factors. Boys and girls are treated somewhat differently and they display somewhat different personality features.

The Big five traits are supposed to be uncorrelated, but this was not the case in the present study (see Table 1). Neuroticism correlates significantly with psychoticism/antisocial personality. Hence, the overlap between personality variables may alter correlations between other variables in the regression model. The advantage of a hierarchical multiple regression approach is that each predictor variable in the regression model is controlled for the effect of the other predictors, allowing the unique contribution of each predictor variable to be identified.

The relationship between family conflicts and school discipline (FSPE:2) and neuroticism, that was found in the second model (i.e. personality factors not included, see Table 2), vanished when the psychoticism/antisocial personality factor entered the final model. The association between the FSPE:2 and neuroticism was, evidently, altered by psychoticism/antisocial personality. This may imply that, without a change in psychoticism/antisocial personality a change in the FSPE:2 (i.e. more or less punishment) may have no effect on neuroticism.

Since FSPE:2, neuroticism and psychoticism/antisocial personality correlates (see Table 1) three tentative paths may be possible. First, do family conflicts and school discipline (FSPE:2) lead to psychoticism/antisocial personality, which leads to neuroticism (i.e. antisocial behaviour elicit anxious behaviour)? Second, does psychoticism/antisocial personality elicit family conflicts (FSPE:2), which leads to neuroticism? Third, does neuroticism elicit family conflicts (FSPE:2), which leads to psychoticism/antisocial personality? No definite answer can be derived from a correlational study.

Twin studies have shown that personality traits correlates for both genetic- and environmental reasons (Ando, Suzuki, Yamagata, Kijima, Maekawa, Ono, \& Jang, 2004; Weiss, Bates, \& Luciano, 2008; Vernon, Villani, Aitken Schermer, \& Petrides, 2008; Rushton, Bons, Ando, Hur, Irwing, Vernon, Petrides, \& Barbaranelli, 2009), which suggest genetic pleiotropy (i.e. the same genes may influence several traits simultaneously), and hence, partly explain why traits inter-correlates.

The strongest predictor of Neuroticism was sex. Girls had higher scores than boys. This has been established elsewhere (Eysenck et al., 1988). In this study, girls experienced more parental warmth and less parental discipline than boys, but displayed higher neuroticism scores, which again indicate a complex relationship between psychosocial environment and neuroticism. Other factors may operate together with gender. Thus, studying other environmental factors (e.g. demands and expectations, sexism etc.) in relation to personality, in gender-discordant sibling pairs, may be a useful approach.

The number of siblings within the family was also a significant predictor of neuroticism. Subjects with many siblings had somewhat higher neuroticism scores. From the child's perspective, the number of siblings is considered as an environmental factor. Perhaps, competition among siblings and less parental attention to the individual child are related to this environmental factor, and thus to neuroticism?

The results in the second part of the FSPE form, i.e. the FPE (relative rating, i.e. children comparing themselves with a sibling), supported the correlational data for FSPE (absolute rating, i.e. differences among all children in the sample). Parental warmth and offers (FPE1) were related to extraversion and parental discipline (FPE2) was related to psychoticism/antisocial personality, whereas none of the FPE factors were related to neuroticism. However, the multiple regression analysis did not yield as clear a picture as for the FSPE factors, possibly because the FPE is primarily designed to assess perception of parenting in sibling pairs. In this study, the children rated parent behavior in comparison with a sibling in the family, who was not tested. If FPE is rated by two siblings, and not only based on one child's comparisons, it may have stronger predictive powers. 
The relationships between parental rejection, low parental warmth and antisocial-related personality variables have been documented in studies with various designs, such as retrospective approach (Kraft \& Zuckerman, 1999), current rating approach (Nishikawa, Sundbom, \& Hägglöf, 2010), observational monozygotic twin difference approach (Pike, McGuire, Reiss, Hetherington, \& Plomin, 1996; Deater-Deckard, Pike, Petrill, Cutting, Hughes, \& O'Connor, 2001) and cross-cultural studies and in meta-analyses (Lila, Garcia, \& Garcia, 2007; Khalegue \& Rohner, 2011).

Family environmental factors could be rated, from a different perspective, by parents, instead of by the children themselves. However, such ratings tend to be more flawed with social desirability, which was shown in a large study on 720 families (Reiss, Plomin, Hetherington, Howe, Rovine, Tryon, \& Stanley, 1994). The children's reports of their psychosocial environment were not in accordance with their parents', but in accordance with observational data (video recordings) of parent-child interaction. Further, children's reports are more strongly associated with observers' ratings of parenting than parents' report (Sessa, Avenevoli, Steinberg, \& Morris, 2001).

Predictions are based on correlational data and hence no conclusions can be drawn about cause-effect relationships. The FSPE factors may lead to anti-social personality or vice versa. Two longitudinal studies indicate that parenting style (psychological control and affection), at one point in time, did predict children's behaviour (internalizing- and externalizing problems), at another point in time (Aunola \& Nurmi, 2005; Wang, Pomerantz, \& Chen, 2007), but even here, cause and effect cannot be determined.

If the FSPE factors are influenced by genotype-environment correlation, two possibilities emerge. First, a reactive genotype-environment correlation may imply that antisocial personality (psychoticism) is at least partly genetically determined. In such case, environment will react upon psychoticism, i.e. teachers, parents, siblings and peers will treat individuals with such a trait differently than others. Second, an active genotype-environment correlation may imply that people with antisocial personalities will search actively for environments that fit his/ her personality disposition (genotype). Thus a next research step is to examine FSPE factors from a behavioral genetic point of view, testing a genotype-environment correlation hypothesis.

\section{Conclusion}

This study has shown correlations between the Family- and School Psychosocial Environment (FSPE) and personality, measured by the Junior Eysenck Personality Questionnaire (J-EPQ), which support socialization theories. Family conflicts and school discipline, and warmth, support and openness from parents, siblings and peers predict psychoticism/antisocial personality and extraversion. Thus, the FSPE has a predictive validity.

Gender did also matter, predicting all the personality variables. The most unexpected finding was the impact of interactions between personality variables themselves, influencing the FSPE's predictability of neuroticism.

\section{Acknowledgements}

I would like to thank all the teachers and children who participated in the study. I would also like to thank Professors Olof Rydén, Martin Bäckström and Fredrik Björklund, Department of Psychology, Lund University, for their valuable comments.

\section{References}

Ando, J., Suzuki, A., Yamagata, S., Kijima, N., Maekawa, H., Ono, Y., \& Jang, K. L. (2004). Genetic and Environmental Structure of Coninger's Temperament and Character Dimensions. Journal of Personality Disorders, 18, 379-393. http://dx.doi.org/10.1521/pedi.2004.18.4.379

Aunola, K., \& Nurmi, J.-E. (2005). The Role of Parenting Styles in Children’s Problem Behaviour. Child Development, 75, 1144-1159. http://dx.doi.org/10.1111/j.1467-8624.2005.00840.x-i1

Bäckström, M., Björklund, F., \& Larsson, M. R. (2009). Five-Factor Inventories Have a Major General Factor Related to Social Desirability Which Can Be Reduced by Framing Items Neutrally. Journal of Research in Psychology, 43, 335-344.

Bornstein, M. H. (2006). Parenting Science and Practice. In K. A. Renninger, \& I. E. Sigel (Eds.), Handbook of Child Psychology: Vol 4. Child Psychology in Practice (6th ed., pp. 893-949). Hoboken, NJ: Wiley.

Clayer, J. R., Ross, M. W., \& Campbell, R. L. (1984). Child-Rearing Patterns and Dimensions of Personality. Social Behavior and Personality, 12, 153-156. http://dx.doi.org/10.2224/sbp.1984.12.2.153

Costa Jr., P. T., \& McCrae, R. R. (1995). Primary Traits of Eysenck’s PEN System: Three- and Five-Factor Solutions. Jour- 
nal of Personality and Social Psychology, 69, 308-317. http://dx.doi.org/10.1037/0022-3514.69.2.308

Deater-Deckard, K., Pike, A., Petrill, S. A., Cutting, A. L., Hughes, C., \& O’Connor, T. G. (2001). Non-Shared Environmental Processes in Social-Emotional Development: An Observational Study of Identical Twin Differences in the Preschool Period. Developmental Science, 4, F1-F6. http://dx.doi.org/10.1111/1467-7687.00157

Eysenck, S. B. G., von Knorring, A.-L., \& von Knorring, L. (1988). A Cross-Cultural Study of Personality: Swedish and English Children. Scandinavian Journal of Psychology, 29, 152-161. http://dx.doi.org/10.1111/j.1467-9450.1988.tb00786.x

Jacobsson, L., Lindström, H., von Knorring, L., Perris, C., \& Perris, H. (1980). Perceived Parental Behaviour and Psychogenic Needs. Archives of Psychiatry and Neurological Sciences, 228, 21-30.

Khalegue, A., \& Rohner, R. P. (2012). Transnational Relations between Perceived Parental Acceptance and Personality Dispositions of Children and Adults: A Meta-Analytic Review. Personality and Social Psychology Review, 16, $103-115$. http://dx.doi.org/10.1177/1088868311418986

Kraft, M. R., \& Zuckerman, M. (1999). Parental Behavior and Attitudes of Their Parents Reported by Young Adults from Intact and Stepparent Families and Relationships between Perceived Parenting and Personality. Personality and Individual Differences, 27, 453-476. http://dx.doi.org/10.1016/S0191-8869(98)00255-4

Lila, M., Garcia, F., \& Garcia, E. (2007). Perceived Paternal and Maternal Acceptance and Children’s Outcome in Colombia. Social Behavior and Personality, 35, 115-124. http://dx.doi.org/10.2224/sbp.2007.35.1.115

Miller, J. D., \& Lynam, D. (2001). Structural Models of Personality and Their Relation to Antisocial Behaviour: A MetaAnalytic Review. Criminology, 39, 765-798. http://dx.doi.org/10.1111/j.1745-9125.2001.tb00940.x

Persson, N. B. G. (1997). Growth Environment and Personality in Adult Migraineurs and Their Migraine-Free Siblings. Headache, 37, 159-168. http://dx.doi.org/10.1046/j.1526-4610.1997.3703159.x

Persson, N. B. G. (2011). Family and School Psychosocial Environment (FSPE): Development of a Brief Questionnaire Measuring Perceived Psychosocial Environments in Children/Siblings. Scandinavian Journal of Psychology, 52, 303-307. http://dx.doi.org/10.1111/j.1467-9450.2010.00868.x

Pike, A., McGuire, S., Hetherington, E. M., Reiss, D., \& Plomin, R. (1996). Family Environment and Adolescent Depression and Antisocial Behavior: A Multivariate Genetic Analysis. Developmental Psychology, 32, 590-603. http://dx.doi.org/10.1037/0012-1649.32.4.590

Plomin, R., \& Daniels, D. (2011). Why Are Children in the Same Family So Different from One Another? International Journal of Epidemiology, 40, 563-582. http://dx.doi.org/10.1093/ije/dyq148

Pomerantz, E. M., \& Thompson, R. A. (2008). Parents Role in Children’s Personality Development. In O. P. John, R. W. Robins, \& L. A. Pervin (Eds.), Handbook of Personality-Theory and Research (3rd ed., pp. 351-374). New York: The Guilford Press.

Reiss, D., Plomin, R., Hetherington, E. M., Howe, G., Rovine, M., Tryon, A., \& Stanley, M. (1994). The Separate Worlds of Teenage Siblings: An Introduction to the Study of the Nonshared Environment and Adolescent Development. In E. M. Hetherington, D. Reiss, \& R. Plomin (Eds.), Separate Social Worlds of Siblings: Impact of Nonshared Environment on Development (pp. 63-109). Hillsdale, NJ: Erlbaum.

Rushton, J. P., Bons, T. A., Ando, J., Hur, Y. M., Irwing, P., Vernon, P. A., Petrides, K. V., \& Barbaranelli, C. (2009). A General Factor of Personality from Multitrait-Multimethod Data and Cross-National Twins. Twin Research and Human Genetics, 12, 356-365. http://dx.doi.org/10.1375/twin.12.4.356

Sessa, F. M., Avenevoli, S., Steinberg, L., \& Morris, A. S. (2001). Correspondence among Informants on Parenting: Preschool Children, Mothers, and Observers. Journal of Family Psychology, 15, 53-68.

http://dx.doi.org/10.1037/0893-3200.15.1.53

Statistics Sweden (2008). Antalsyskon 2011. Statistic Sweden. http://www.ssd.scb.se/databaser/makro/Produkt.asp?produktid=LE0102\&lang=1

Svensson, B., Långberg, B., \& Janson, S. (2007). Våld mot barn 2006-2007. En nationell kartläggning. http://www.barnrattsdagarna.se/fileadmin/user_upload/dokument/2012/pdf/v_ldmotbarn.pdf

Vernon, P. A., Jang, K. L., Harris, J. A., \& McCarty, J. M. (1997). Environmental Predictors of Personality Differences: A Twin and Sibling Study. Journal of Personality and Social Psychology, 72, 177-183. http://dx.doi.org/10.1037/0022-3514.72.1.177

Vernon, P. A., Villani, V. C., Schermen, J. A., \& Petrides, K. V. (2008). Phenotypic and Genetic Associations between the Big Five and Trait Emotional Intelligence. Twin Research and Human Genetics, 11, 524-530. http://dx.doi.org/10.1375/twin.11.5.524

Wang, Q., Pomerantz, E. M., \& Chen, H. C. (2007). The Role of Parents’ Control in Early Adolescents’ Psychological Functioning: A Longitudinal Investigation in the United States and China. Child Development, 78, 1592-1610. 
http://dx.doi.org/10.1111/j.1467-8624.2007.01085.x

Weiss, A., Bates, T. C., \& Luciano, M. (2008). Happiness Is a Personal(ity) Thing: The Genetics of Personality and WellBeing in a Representative Sample. Psychological Science, 19, 205-210.

http://dx.doi.org/10.1111/j.1467-9280.2008.02068.x 